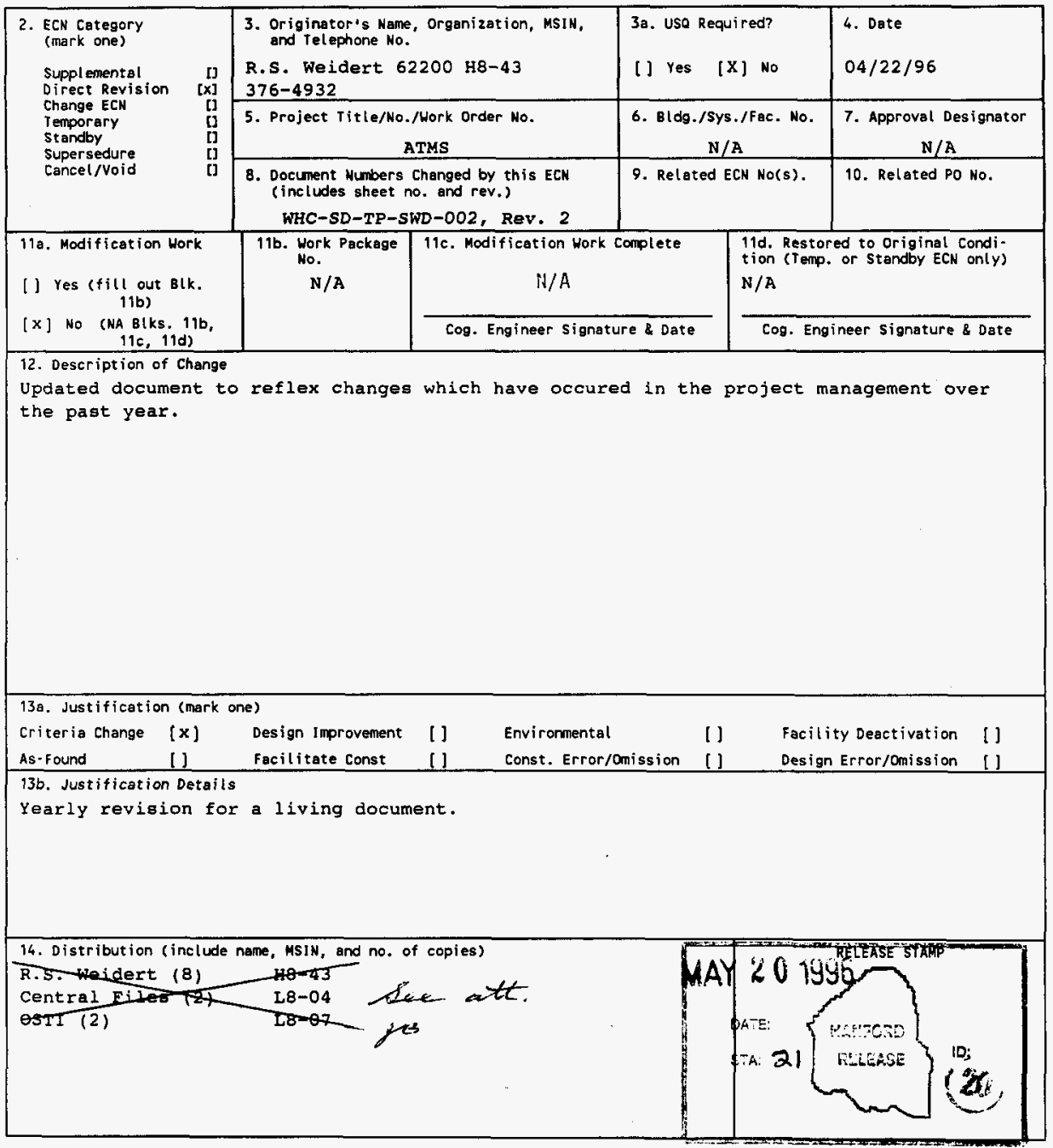




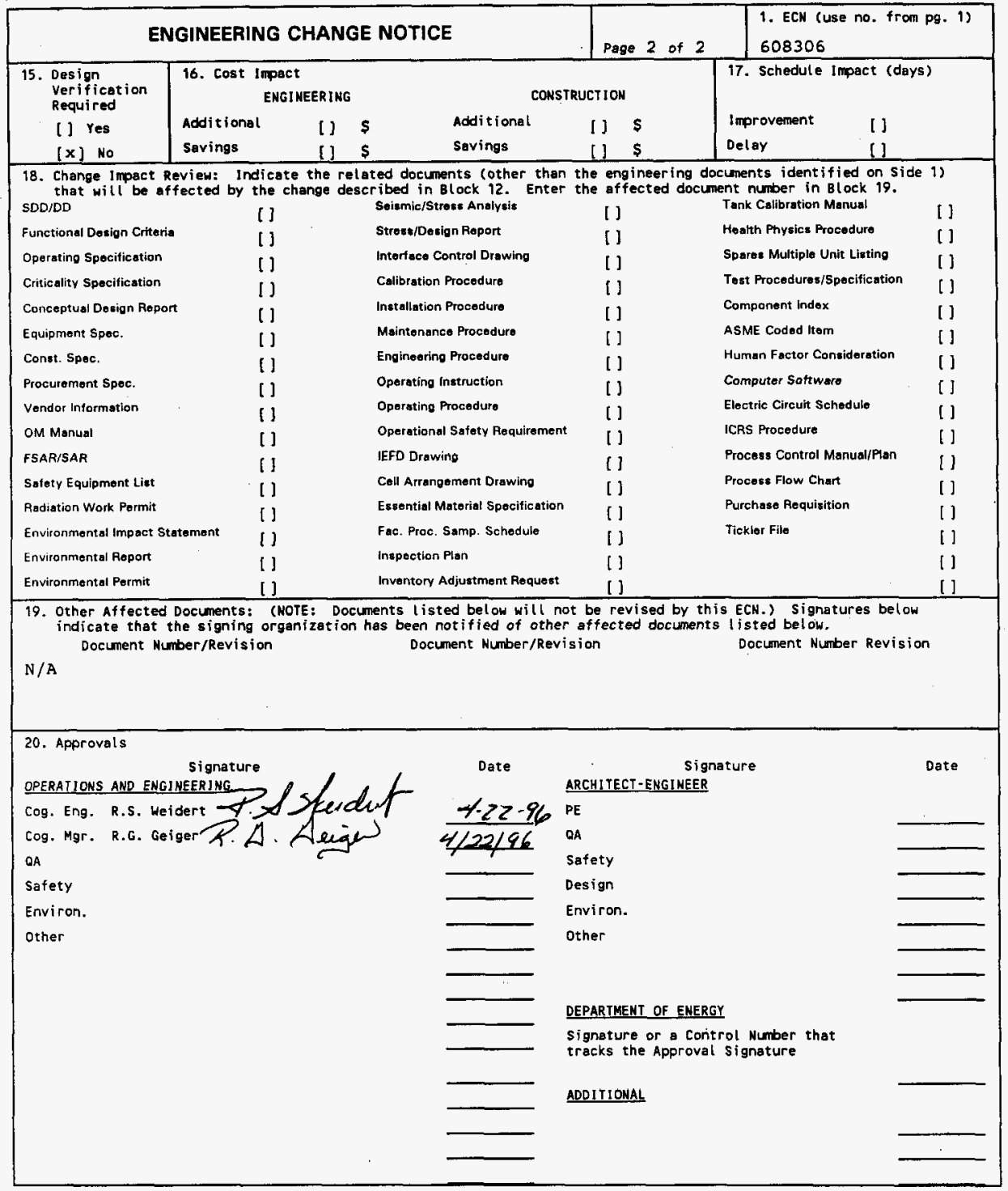




\title{
Automated Transportation Management System (ATMS) Software Project Management Plan (SPMP)
}

\author{
R.s. Weidert \\ Boeing Computer Services - Richland, Richland, WA 99352 \\ U.S. Department of Energy Contract DE-ACO6-87RL10930 \\ EDT/ECN: 608306 UC: 905 \\ Org Code: 62200 Charge Code: R60206 \\ BER Code: EW5010006 Total pages: 42 \\ Key Words: ATMS, Software, SPMP, IPC, Technical Project Manager \\ Abetract: The Automated Transportation Management syotem (ATMS) \\ Software Project Management plan (SPMP) is the lead planning document \\ governing the life cycle of the ATMS and its integration into the \\ Transportation Information Network (TIN). This SPMP defins the project \\ tasks, deliverables, and high level schedules involved in developing the \\ client/server ATMS software.
}

TRADEMARK DISCLAIMER. Reference herein to any specific comercial product, process, or service by trade name, trademark, manufacturer, or otherwise, does not necessarily constitute or imply its endorsement, recommendation, or favoring by the United states Government or any agency thereof or its contractors or subcontractors.

Printed in the United States of America. To obtain copies of this document, contact: HHC/BCS Document Control Services, P.O. Box 1970, Mailstop H6-08, Richland WA 99352, Phone (509) 372-2420; Fax (509) 376-4989.
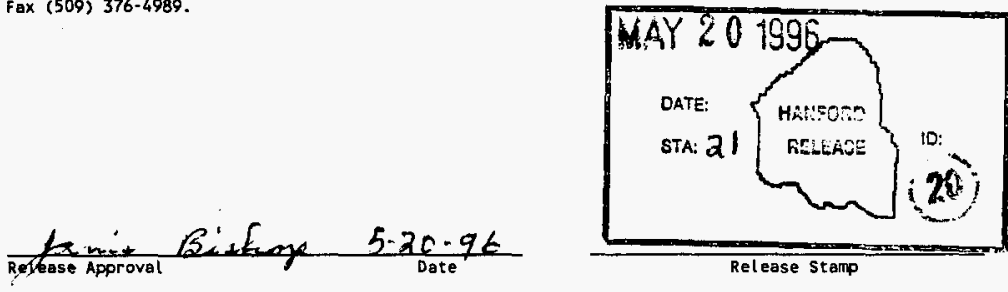

Release Stamp

\section{Approved for Public Release}




\section{RECORD OF REVISION}

(2) Title

Automated Transportation Management system (ATMS) Software Project Management Plan (SPMP)

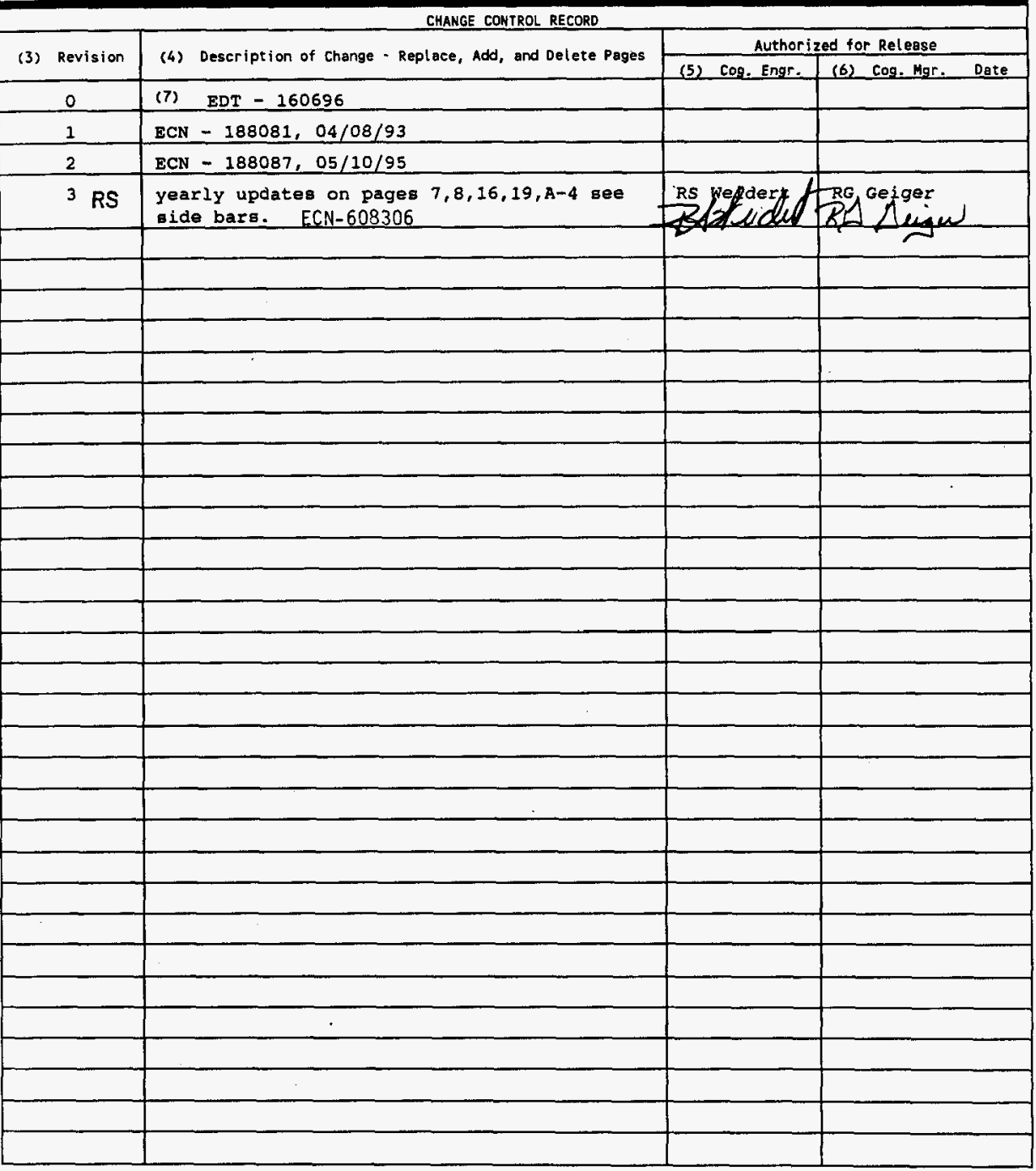


WHC-SD-TP-SWD-002 Rev. 3

AUTOMATED TRANSPORTATION MANAGEMENT SYSTEM (ATMS)

SOFTWARE PROJECT MANAGEMENT PLAN (SPMP)

April 22, 1996

\author{
Issued by \\ Westinghouse Hanford Company \\ for the \\ U. S. Department of Energy \\ Richland Operations office \\ Richland, Washington
}


WHC-SD-TP-SWD-002 Rev. 3

This page intentionally left blank. 
WHC-SD-TP-SWD-002 Rev. 3

GLOSSARY

The definitions and terminology used in this document are documented in American National standards Institute (ANSI) / Institute of Electrical and Electronics Engineers (IEEE) 610.12-1990, Standard Glossary of software Engineering Technology (ANSI/IEEE 1990). Definitions which may be of special interest to the reader, deviations, and additions are defined in this section. Acronyms and initialisms are also defined.

\section{ACRONYMS AND INITIALISMS}

$\begin{array}{ll}\text { ANSI } & \text { American National standards Institute } \\ \text { ATMS } & \text { Automated Transportation Management System } \\ \text { BCSR } & \text { Boeing Computer Services Richland } \\ \text { CMP } & \text { Configuration Management Plan } \\ \text { DBA } & \text { Database Administrator } \\ \text { DOE } & \text { Department of Energy } \\ \text { EDI } & \text { Electronic Data Interface } \\ \text { EDT } & \text { Engineering Data Transmittal } \\ \text { FY } & \text { Fiscal Year } \\ \text { GOCO } & \text { Government Owned Contractor operated } \\ \text { GSA } & \text { General Services Administration } \\ \text { GUI } & \text { Graphical User Interface } \\ \text { IEEE } & \text { Institute of Electrical and Electronics Engineers } \\ \text { IPC } & \text { Integrated Program Coordinator } \\ \text { IRM } & \text { Information Resource Management } \\ \text { ISS } & \text { Information and Scientific Systems } \\ \text { LAN } & \text { Local Area Network } \\ \text { LANL } & \text { Los Alamos National Labs } \\ \text { QA } & \text { Quality Assurance } \\ \text { RDBMS } & \text { relational database management system } \\ \text { SDD } & \text { Software Design Document } \\ \text { SLIP } & \text { Serial Line Interface Protocol } \\ \text { SMAC } & \text { Shipment Mobility/Accountability Collection } \\ \text { SPMP } & \text { Software Project Management Plan } \\ \text { SRS } & \text { Software Requirementa Specification } \\ \text { SVVP } & \text { System Verification and Validation Plan } \\ \text { TIN } & \text { Transportation Information Network } \\ \text { TMD } & \text { Transportation Management Division } \\ \text { VVR } & \text { Verification and Validation Review } \\ \text { VEV } & \text { Verification and Validation } \\ \text { WBS } & \text { work breakdown structure } \\ \text { WHC } & \text { Westinghouse Hanford Company } \\ & \end{array}$




\section{DEFINITIONS}

Acceptance Testing. Formal testing conducted to determine whether or not a system aatiofies ito acceptance criteria and to enable the customer to determine whether or not to accept the system.

Adaptive Maintenance. Software maintenance performed to make a computer program usable in a changed environment.

Configuration control. An element of configuration management, consisting of the evaluation, coordination, approval or disapproval, and implementation of changes to configuration items after formal establishment of their configuration identification.

Corrective Maintenance. Maintenance performed to correct faults in hardware or software.

Design Phase. The period of time in the software life cycle during which the designs for architecture, software components, interfaces, and data are created, documented, and verified to satisfy requirements.

Implementation phase. The period of time in the software life cycle during which a software product is created from design documentation and debugged.

Installation Phase. The period of time in the software life cycle during which a software product is integrated into its operational environment and tested in this environment to ensure that it performs as required.

Module. (1) A program unit that is discrete and identifiable with respect to compiling, combining with other units, and loading. (2) A logically separable part of a program.

Perfective Maintenance. Software maintenance performed to improve the performance, maintainability, or other attributes of a computer program.

Software Design Description (SDD). A representation of software created to facilitate analysis, planning, implementation, and decision making. The SDD is used as a medium for communicating software design information, and may be thought of as a blueprint or model of the system.

Software Requirements specification. Documentation of the essential requirements (functions, performance, design constraints, and attributes) of the software and its external interfaces.

Test Phase. The period of time in the software life cycle during which the componente of a software product are evaluated and integrated, and the software product is evaluated to determine whether or not requirements have been satisfied. 
Test Plan. A document describing the technical and management approach to be followed for teating a system or component. It identifies the items to be tested, tasks to be performed, responsibilities, schedules, risks, and required resources for the testing activity.

Verification and Validation (Vsv). The process of determining whether the requirementa for a system or component are complete and correct, the products of each development phase fulfill the requirements or conditions imposed by the previous phase, and the final system or component complies with specified requirements. 
WHC-SD-TP-SWD-002 ReV. 3

This page intentionally left blank. 
CONTENTS

1.0 INTRODUCTION . . . . . . . . . . . . . . . . . . . . . . 1

1.1 PURPOSE . . . . . . . . . . . . . . . . . . . . . . . . . . 2

1.2 SCOPE . . . . . . . . . . . . . . . . . . . . . . . . . . . 2

1.3 OVERVIEW . . . . . . . . . . . . . . . . . . . . . . . . . . . 2

1.4 DELIVERABLES . . . . . . . . . . . . . . . . . . . . . . . . . 3

1.4.1 Hardware/Operating system Software . . . . . . . . . . 3

1.4 .2 Software... . . . . . . . . . . . . . . . 3

1.4 .3 Documentation ................ . . 4

2.0 PROJECT ORGANIZATION . . . . . . . . . . . . . . . . . . . . . 5

2.1 PROCESS MODEL . . . . . . . . . . . . . . . . . . . . . . . 5

2.2 ORGANIZATIONAL STRUCTURE . . . . . . . . . . . . . . . . . . . . . . 7

2.3 ORGANIZATIONAL BOUNDARIES AND INTEREACES . * . . . . . . . . . . 7

2.4 PROJECT RESPONSIBILITIES . . . . . . . . . . . . . . . . . 9

3.0 MANAGERIAI PROCESS . . . . . . . . . . . . . . . . . . . . . . . . . 11

3.1 MANAGEMENT OBJECTIVES AND PRIORITIES . . . . . . . . . . . . . 11

3.2 ASSUMPTIONS, DEPENDENCIES, AND CONSTRAINTS . . . . . . . . . . 12

3.3 ACCEPTANCE CRITERIA . . . . . . . . . . . . . . . . . . . . 12

3.4 RISK MANAGEMENT . . . . . . . . . . . . . . . . . . . . . . 12

3.5 MONITORING AND CONTROLLING MECHANISMS . . . . . . . . . . . . 13

3.6 STAFFING PLAN . . . . . . . . . . . . . . . . . . . . . 14

4.0 TECHNICAL PROCESS . . . . . . . . . . . . . . . . . . . . . . 16

4.1 METHODS, TOOLS, AND TEChNIQUES . . . . . . . . . . . . . . . . 16

4.1 .1 standards . . . . . . . . . . . . . . . . . . . 16

4.1 .2 Hardware/software . . . . . . . . . . . . . . . 16

4.1.3 Testing . . . . . . . . . . . . . . . . . 17

4.2 Documentation . . . . . . . . . . . . . . . . . . . . . . . . 18

4.3 CONFIgURATION CONTROL . . . . . . . . . . . . . . . . . . . 18

4.4 ACQUISITION . . . . . . . . . . . . . . . . . . . . . . . . . . 20

4.5 DATA MANAGEMENT . . . . . . . . . . . . . . . . . . . . . 20

5.0 VERIFICATION AND VALIDATION PLANNING . . . . . . . . . . . . . . . . 21

5.1 OVERVIEW . . . . . . . . . . . . . . . . . . . . . . . . . . . 21

5.2 DEVELOPMENT CYCLE VERIFICATION AND VALIDATION . . . . . . . . 21

5.3 TRAINING . . . . . . . . . . . . . . . . . . . . . . . . 21

6.0 WORK PACKAGES, SCHEDULE, AND BUDGET . . . . . . . . . . . . . . . . . 23

6.1 WORK PACKAGES . . . . . . . . . . . . . . . . . . . . . . . 23

6.2 DEPENDENCIES . . . . . . . . . . . . . . . . . . . . . . . . 23

6.3 RESOURCE REQUIREMENTS . . . . . . . . . . . . . . . . . . . . . 23

6.4 SCHEDULE ............................. . . . . . . . . 23

7.0 REFERENCES . . . . . . . . . . . . . . . . . . . . . . . . . . . . 24

APPENDIX A. ATMS WORK BREAKDOWN STRUCTURE . . . . . . . . . . . . . . . A-3 
WHC-SD-TP-SWD-002 Rev. 3

FIGURES

Figure 2-1. Typical system Process Phases. . . . . . . . . . . . . . . . 6

Figure 2-2. ATMS/IRM Organizational Management structure. . . . . . . . 8

TABLES

2-1. Automated Transportation Management syatem Activity Responsibility Matrix. . . . . . . . 10 
WHC-SD-TP-SWD-002 Rev. 3

\section{AUTONATED TRANSPORTATION MANAGEMENT SYSTEM SOFTWARE PROJECT MANAGEMENT PLAN}

\subsection{INTRODUCTION}

As a cabinet level federal agency with a diverse range of misaions and an infrastructure spanning the United States, the U.S. Department of Energy (DOE) has extensive freight transportation requirements. Performance and management of this freight activity is a critical function. DOE's Transportation Management Division (TMD) has an agency-wide responsibility for overseeing transportation activities.

Actual transportation operations are handled by government or contractor staff at the field locations. These staff have evolved a diverse range of techniques and procedures for performing transportation functions. In addition to minimizing the economic impact of transportation on programs, facility transportation staff must be concerned with the increasingly complex task of complying with complex shipment safety regulations. Maintaining the department's safety record for shipping hazardous and radioactive materials is a primary goal.

Use of automation to aid transportation functions is not widespread within DOE, though TMD has a number of software systems designed to gather and analyze data pertaining to field transportation activities. These systems are not integrated. Historically, most field facilities have accomplished transportation-related tasks manually or with minimal computer assistance. At best, information and decision support systems available to transportation gtaffs within the facilities are fragmented. In deciding where to allocate resources for automation, facility managers have not tended to give the needs of transportation departments a high priority. This diversity causes TMD significant difficulty in collecting data for use in managing department-wide transportation activities.

The Automated Transportation Management System (ATMS) was initiated in response to a number of actions. The DOE transportation personnel had long realized that automation was needed, but lacked the upper management support for funding to develop and implement automation systems. The automation initiative received higher visibility with the passage of Public Law 99-627 (November 7,1986 ). Section 2 of this law directed the government to study the feasibility of automating the freight transportation management function. The DOE responded by designating a task force to examine the potential role of automation in transportation within its complex. The task force consisted of transportation and systems experts from the ranks of the DOE and its contractors. Initial reportg generated by this group concluded that the project was feasible and made recommendations regarding how the automation project should be purgued. Furthermore, a 1989 audit of transportation by the DOE Inspector General resulted in a finding that automation would allow transportation personnel to achieve sizable savings through prepayment audits. Based on these recommendations, the Department has elected to develop and implement the ATMS.

The Automated Transportation Management system (ATMS) Software Project Management Plan (SPMP) is the lead planning document governing the life cycle of the ATMS and its integration into the Transportation Information Network 
(TIN). The ATMS is a sute of applications which oupport transportation office needs for the DOE complex. As a part of this suite, this plan will be reviewed on a periodic basis and revised when necessary to reflect changes in baseline design concepts and schedules. At a minimum, the plan will be revised on a yearly basis to reflect the work to be accomplished in the next fiscal year (FY).

\subsection{PURPOSE}

This SPMP will define the project tasks, deliverables, and high level achedules involved in developing the client/server ATMS software. The ATMS is comprised of many modules. Each module supports a major function within transportation. The purpose of this sPMP is to outline the process followed to develop a modules to support one of these functions. Each modules will be developed as a separate entity.

As each module is completed, it will enter into the production environment. None of the modules being developed to support the transportation needs of the DOE complex are considered to be sensitive or quality affecting systems.

\subsection{SCOPE}

The scope of this document is limited to the management of the module development and the deployment of these modules with the server hardware to identified regional DOE sites. Within the organization of the project, the managerial process, the technical process, the verification and validation plan, work packages, and schedule will be addressed. This document does not constitute an official statement of product requirements. The requirements for each of the modules to be developed are addressed in their respective System Requirements Specifications (SRS). Once the deployment of hardware and software covered in this plan has occurred, it is the responsibility of the receiving site to manage, or to contract the management, of the system as outlined in the ATMS installation plan and the ATMS administration and operations guide.

\subsection{OVERVIEW}

This document describes all aspects of managing the project development one module at a time. Even though development of some modules will be done in tandem, this plan does not differentiate between them. Chapter 2.0 contains the organizational structure, boundaries, interfaces, and responsibilities of this project. A life cycle model will be described and illustrated in this chapter. Chapter 3.0 describes the management objectives, priorities, assumptions, dependencies, and constraints of this project, and discusses the risks involved and the mechanisms used to monitor and control the scheduled activities. A atafing plan is also presented in this section. chapter 4.0 addresses the methods, tools, and techniques of the technical development process. It will also describe about the software documentation and project support functions. Chapter 5.0 describes the verification and validation plan. This will include a detailed plan for the verification and validation tasks throughout the development, how results will be documented, 
WHC-SD-TP-SWD-002 Rev. 3

administrative procedures, standards, practices, and conventions. Chapter 6.0 describes the work packages, dependencies, resource requirements, costs, resource allocation, and schedule for modules currently under development. chapter 7.0 contains project references.

\subsection{DELIVERABLES}

The ATMS project deliverables include server computer hardware, client and server software, and documentation in three areas: planning, definition, and operational. The ATMS development and engineering activities follow WHC-CM-6-1, Standard Engineering Practices (WHC 1988b) and WHC-CM-3-10, Software Practices (WHC 1993a). In addition, the ATMS Software Documentation Plan, WHC-SD-TP-PIN-007 (WHC 1993b), which outlines all the documentation on the project, has been prepared.

\subsubsection{Hardware/Operating System Software}

The acquisition of suitable server hardware was completed prior to implementation and release of the first software module. This platform includes vendor-provided software, such as operating system, relational database management software (RDBMS), and communications software. Graphical Uger Interface (GUI) software, report generators, library utilities, language compilers, and telecommunications software have also been acquired for the . client computers. The hardware platforms have been purchased by the Westinghouse Hanford company (WHC) in Richland washington. The vendor provided software and the RDBMS will be loaded and configured by personnel at the whC prior to delivery to regional delivery.

\subsubsection{Software}

The functional software definition for ATMS is contained in the Functional Requirements for the Automated Transportation Management system, DOE/RL-93-17 (DOE-RL 1993a). The software requirements for each module are contained within the software Requirements specification (SRS) for each module. The detailed design specifications for the ATMS software structure will be found in the ATMS Software Design Description (SDD), WHC-SD-TP-0O1 (WHC 1995a). Software control will be in accordance with Westinghouse Hanford Company (WHC) standard policies and procedures including WHC-CM-6-1, Standard Engineering Practices (WHC 1988b), and WHC-CM-3-10, software Practices (WHC 1993 a).

The software, developed in accordance with the ATMS SDD, will be initially installed on the production servers and client computers by trained personnel. Installation on the servers will take place prior to the hardware being sent to the regional sites. Once loaded, it will be tested in accordance with the ATMS Test Plan, WHC-SD-TP-TP-002 (WHC 1994). After the server has passed its production readiness test, it is ready for delivery to the regional sites. Trained personnel will accompany the server to the installation site for setup and testing. After the server is installed, the client software will be loaded on several users computers so that installation testing can be performed. Persons not trained in product installation will be 
WHC-SD-TP-SWD-002 Rev. 3

able to accomplish installation on other client computers once testing is complete.

\subsubsection{Documentation}

All custom software documentation will adhere to wHC policies and applicable ANSI/IEEE software engineering standards. All documentation for the system will be available in hard copy or electronically. The electronic format will be WordPerfect.

Each document to be produced will undergo peer review, and all major documents will be formally reviewed by the Verification and Validation (V\&V) process. All documents will be reviewed, approved, and distributed in accordance with WHC-CM-6-1, Standard Engineering Practices (WHC 1988b).

The following documents will be produced and issued as supporting documents. Those preceded with an asterisk $(*)$ will be produced for each module. Those preceded with the pound aign (\$) will be sent with the hardware to each regional site.

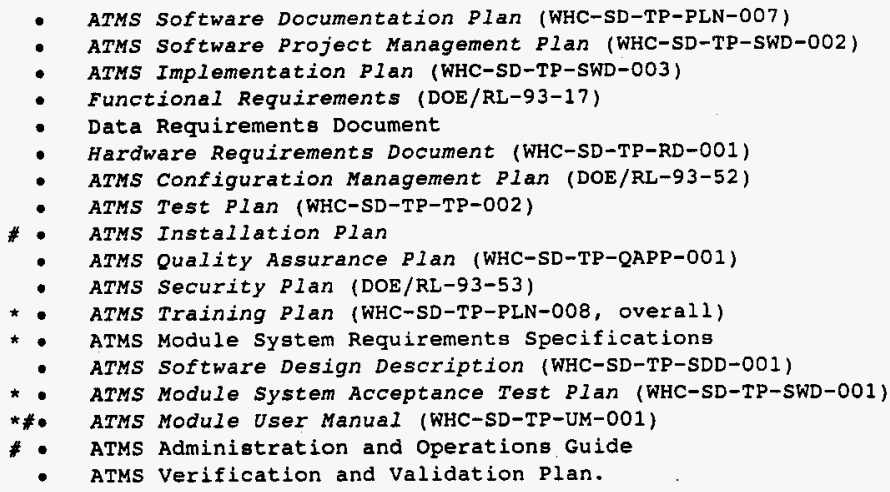

\footnotetext{
${ }^{1}$ WordPerfect is a trademark of the WordPerfect Corporation.
} 


\subsection{PROJECT ORGANIZATION}

The ATMS project organizational structures and relationships, boundaries and interfaces, authorities, and responsibilities are identified and fully described in the chapter.

\subsection{PROCESS MODHL}

The system development process described in the following paragraphs follows life cycle methodology used by WHC (WHC-CM-4-2, Quality Assurance Manual, QR 19.0 (WHC 1989b)) and IEEE (ANSI/IEEE 729-1989, Section 5, Software Iife Cycle). Chapter 4.0 of this SPMP describes specific engineering tasks required to complete each process phase.

The ATMS process for each module includes concept, requirements, design, implementation, testing, installation, checkout, operation and maintenance, and retirement phases. The interaction, overlap, and dependencies between phases are complex, and it must not be assumed that all agpects of one phase end when another begins. Because some of the modules will be developed in tandem, similar phases may be combined on some modules. Some completed tasks could require rework because of new customer requirements or design review findings. In such cases, a portion of the development sequence may be reiterated and lag behind the main effort. A good design can be viewed as a continuum of activities that constantly interact in support of each other. Figure 2-1 illustrates the phases.

The module process phases are as follows:

- Concept Phase - The project proposal associated with the system to be designed.

- Requirements Phase - The development is planned and the requirements for a system product, such as the functional and performance capabilities, are defined and documented.

- Design Phase - The designs for architecture, components, interfaces, and data structures are created, documented, and verified to satisfy reguirements.

- Implementation Phase - The product is created from design documents, debugged, and prepared for formal testing.

- Test Phase - The product is evaluated to determine if requirements have been satisfied.

- Installation Phase - The product is integrated into an operational environment and tested to ensure that it performs as required. 


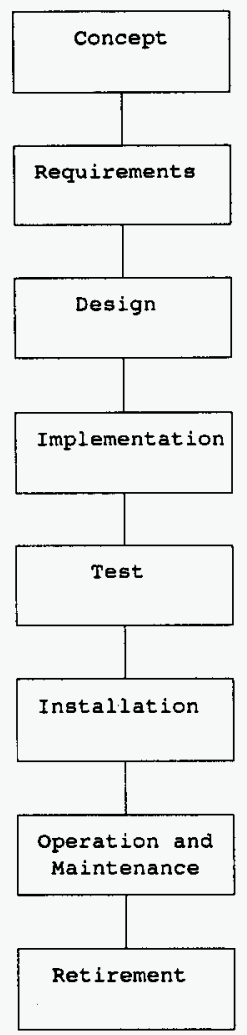

Figure 2-1. Typical System Process Phases. 
WHC-SD-TP-SWD-002 Rev. 3

- Operation and Maintenance Phase - The product is employed in its operational environment, monitored for atiafactory performance, and modified as necessary to correct problems or to respond to changing requirements.

- Retirement Phase - The support for the product is terminated.

\subsection{ORGANIZATIONAI STRUCTURE}

The ATMS project organization is illustrated in Figure 2-2. Within the ATMS project organization, DOE-HQ EM261 has responsibility for the overall ATMS development and implementation. The ATMS Users Group, made up of cognizant personnel including traffic managers from multiple sites, will provide transportation specific technical support to assist Information Regource Management (IRM) staff in performing the work of system design and implementation. Management responsibilities for the ATMS development was delegated to IRM starting in FY 1993. Figure 2-2 shows the ATMS functional users organizations structure, lines of authority, and responsibilities along with the IRM organization structure, lines of authority and responsibilities.

Under the direction and support of DOE-HQ, a team concept is being used to accomplish the ATMS design and development activities. The team consists of subject matter experts from the DOE complex and developers from three DOE Goco facilities working together to develop the ATMS. Team expertise ranges from engineering to operations. The technical project management role in organizing this team is being provided by the Westinghouse Hanford Company/Boeing Computer Services - Richland (WHC/BCSR).

The ATMS IRM staff includes developers from two developing sites. The staff and their individual responsibilities are described in section 3.6 . The IRM staff, as well as individual contributors from the Transportation user organization, will design and implement the ATMS. An IRM ATMS project manager will lead the ATMS staff in the system design, testing, and implementation.

After acceptance testing of each module and turnover of the ATMS to software maintenance, it is anticipated that a staff of computer operations personnel and software engineers will be required to run and maintain the system software.

All ATMS project support functions will be structured to make maximum use of the existing project support groups, systems, and procedures for each module within the ATMS. These functions include the financial reporting system, document control, technical editing, and administration of project training records.

\subsection{ORGANIZATIONAI BOUNDARIES AND INTERFACES}

A significant coordination effort will be required between subject matter experts from all interested sites and the IRM development team to implement project activities. Communications among subject matter experts, the V\&V team, hardware and software engineers and the development team will be required throughout system development. Each organization will be kept informed of the status of the project and cross trained to the extent that 


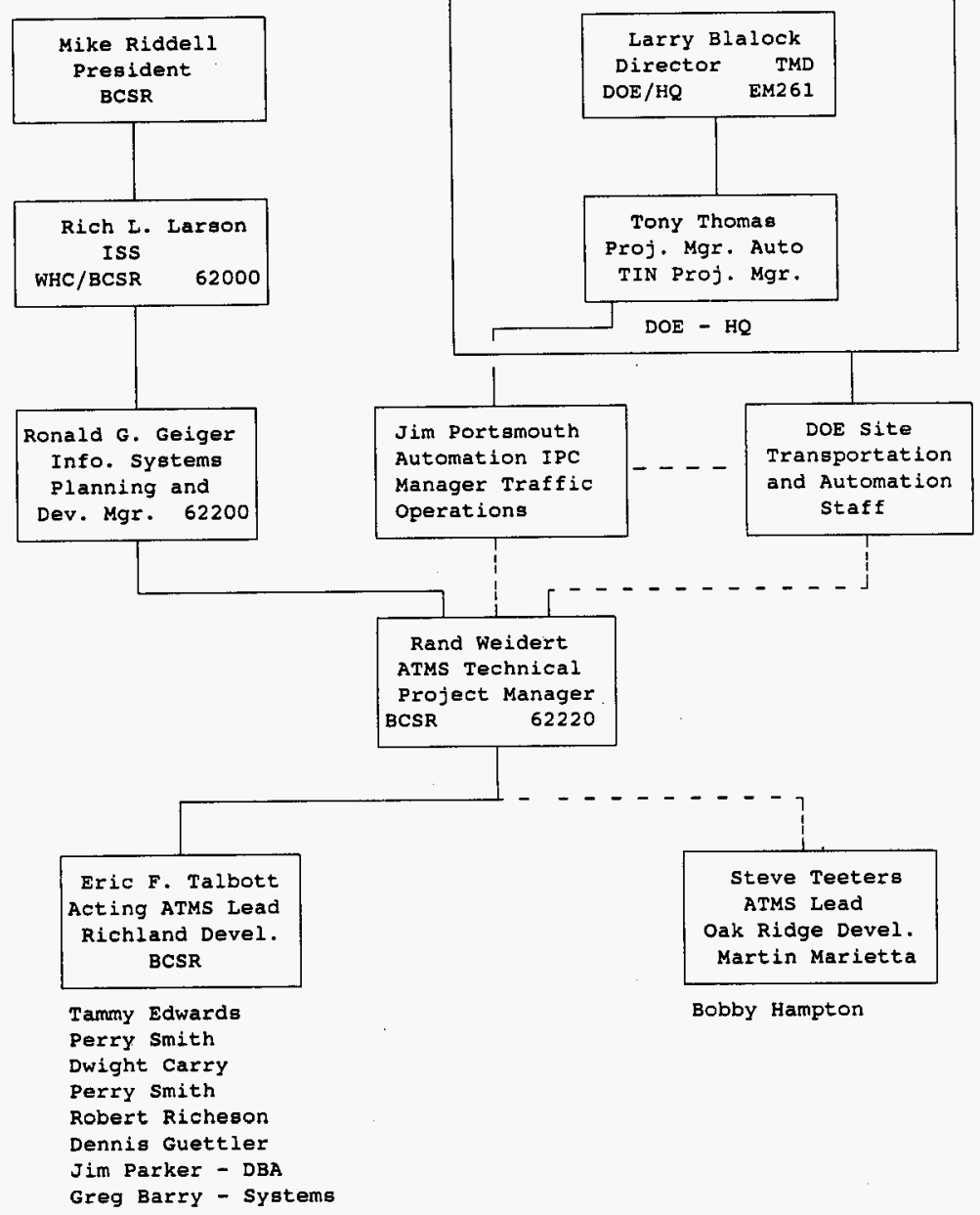

Figure 2-2. ATMS/IRM Organizational Management structure. 
WHC-SD-TP-SWD-002 ReV. 3

reasonable technical coverage will be available for peer reviews, VaV, and reviews.

The level of interface activity required between the ATMS Technical Project Manager and the ATMS Leads at each of the developing 8 ite is anticipated to be approximately 10 percent of each individual's time. The level of interface activity required between the aTMs Technical Project Manager and the Integrated Program Coordinator (IPC) is anticipated to be approximately 10 percent of each individual's time.

The DOE Site Transportation and Automation Staff will provide technical direction to the ATMS project through the ATMS Users Group. The IRM ATMS Technical Project Manager will deliver technical input and receive approval through the IPC and ATMS Users Group. All membere of the ATMS Users Group and Transportation and Automation staff will have free communication access to the Technical Project Manager on all matters relating to the ATMS project. Request for information from the IPC will be processed as quickly as possible.

Significant technical exchange and interface reguirements are expected among the ATMS development staff, other IRM groups across the complex, and subject matter experts. Therefore, the ATMS Technical Project Manager will maintain the responsibility to monitor all interfaces with ATMS development staff team members. Unscheduled interfaces with the ATMS development staf team members could and will geverely impact the ATMS development process. With consideration to this concern, the IPC will be granted free access to all ATMS personnel. Other ATMS subject matter experts will work through the IPC to resolve issues. When specific action is required to correct a deficiency, the ATMS Technical project Manager will be informed and will initiate the appropriate corrective action.

\subsection{PROJECT RESPONSIBILITIES}

Table 2-1 shows the ATMS activities and the responsible organization(s). ATMS subject matter experts will assist ATMS software engineers in the development of the ATMS, including review and final approval of all deliverables. The V\&V program will be conducted as a parallel activity with the ATMS development effort by personnel at LANL. The V\&V team is responsible for documentation reviews, writing VVRs and documentation, system testing, and audits. The final VVR will serve as the ATMS system certification. The development team (ATMS software engineers) will design, develop, and implement the ATMS in accordance with scheduled ATMS project milestones. 
Table 2-1. Automated Transportation Management System Activity Responsibility Matrix.

\begin{tabular}{|c|c|c|c|}
\hline ATMS Activities & Trangportation & V\&V & IRM \\
\hline Technical Exchange Meetings & $\mathrm{x}$ & $\mathrm{X}$ & $\mathrm{x}$ \\
\hline Acceptance Criteria & $\mathbf{x}$ & & $\mathrm{x}$ \\
\hline Software Requiremente Specification & $\mathrm{x}$ & & $\mathrm{x}$ \\
\hline Functional Requirements Document & $\mathbf{x}$ & & $\mathbf{x}$ \\
\hline Data Requirements Document & & & $\mathrm{x}$ \\
\hline Hardware Requirements Document & & & $\mathrm{x}$ \\
\hline Strategic Project Management Plan & & & $\mathrm{x}$ \\
\hline Verification and Validation Plan & & $\mathrm{x}$ & \\
\hline Test Plan & & & $\mathrm{x}$ \\
\hline Implementation Plan & & & $x$ \\
\hline Software Documentation Plan & & & $\mathrm{x}$ \\
\hline Security Plan & & & $\mathrm{x}$ \\
\hline Quality Assurance Plan & & & $x$ \\
\hline Configuration Management Plan & & & $x$ \\
\hline Installation Plan & & & $x$ \\
\hline Training Plan & & & $\mathrm{x}$ \\
\hline Maintenance Plan & & & $\mathrm{x}$ \\
\hline Conversion Plan & & & $x$ \\
\hline Software Design Description & & & $x$ \\
\hline User Manuals & & & $\mathrm{x}$ \\
\hline Operating Procedures & $\mathrm{x}$ & & $\mathrm{x}$ \\
\hline Software source Listing & & & $\mathrm{x}$ \\
\hline Software Development & & & $x$ \\
\hline Software Unit Development Folders & & & $\mathrm{x}$ \\
\hline Administration and Operations Guide & & & $\mathrm{x}$ \\
\hline Training Manuals & & & $\mathrm{x}$ \\
\hline Requirements Traceability Matrix & & & $\mathrm{x}$ \\
\hline Requirements Review VVR & & $x$ & \\
\hline Preliminary Design Review VVR & & $\mathrm{x}$ & \\
\hline Detailed Design Review VVR & & $\mathrm{x}$ & \\
\hline Operational Test Results & $\mathbf{x}$ & $x$ & \\
\hline Final VVR & & $\mathrm{x}$ & \\
\hline Installation and checkout & $\mathrm{x}$ & $\mathrm{x}$ & $\mathrm{x}$ \\
\hline Operation and Maintenance & & & $\mathrm{x}$ \\
\hline
\end{tabular}




\subsection{MANAGERIAL PROCESS}

This chapter describes the managerial process for the ATMS project. The areas covered include management objectives, priorities, assumptions, dependencies, constraints, risk management, and staffing.

\subsection{MANAGEMENT OBJECTIVES AND PRIORITIES}

The management objective for the ATMS project is to complete the project on schedule, within budget, and in compliance with each of the module sRss. The ATMS project will adhere to ANSI/IEEE standards and all requirements defined in wHC-CM-6-1, standard Engineering Practices (WHC 1988b), WHC-CM-3-10, Software Practices (WHC 1993a), and WHC-CM-4-2, Quality Assurance Manual (WHC 1989b). The management philosophy for this project is to complete the ATMS project in an orderly and business-like manner according to established ANSI/IEEE standards for software development.

Implementing each of the ATMS modules include developing a V\&V plan to insure the quality and functionality of the project. The V\&V activity will be conducted in parallel with the ATMS development effort. The V\&V plan addresses all phases of the ATMS project including SRS, SDD, Installation Plan, Test Plan, and Training Plan.

Changes and/or enhancements to any of the module requirements or detailed design which occur after final approval of the requirementa or detailed design, will be incorporated into the existing plan according to established change-control procedures. The IRM ATMS Technical Project Manager will provide, at a minimum, monthly written status reports to the IPC, and IRM management on the progress of the ATMS development.

Priorities for developing ATMS include:

1. Meet the requirements of the SRSs for each module being developed.

2. Follow established software development standards which ensure quality software and meet system impact level requirements.

3. Complete the project on schedule.

4. Complete the project within budget.

5. Implement standardized project management procedures and practices to oversee each module development effort for ATMS.

6. Minimize costs by sharing technologies, expertise and effort from module to module independent of contractor. 
WHC-SD-TP-SWD-002 Rev. 3

\subsection{ASSURTIONS, DEPENDENCIES, AND CONSMRAINTS}

Ongoing support from the ATMS subject matter experts who have been identified is assumed for all phases of the ATMS development. It ia recognized that the eubject matter experts for each module will be different and that identifying experts for each module is required for the success of the module development. The Project thus far has had the desired support. A greater level of aupport will be required from selected sites now that the system has entered the test phases.

\subsection{ACCEPTANCE CRITERIA}

The acceptance criteria for this system is detailed in the acceptance criteria for each module. The acceptance of this gyatem will be based on the performance of the system to this criteria.

\subsection{RISK MANAGEMENT}

The following development risks have been identified for ATMS. The first set of risks are the most severe and would prevent the project from meeting project requirements.

- Hardware or software not available for development, initial implementation, or final implementation. - To minimize this potential risk, all hardware and software acquisitions will be done from the Richland Operations office. An acquisitions specialist at that site has been assigned for the acquisition of hardware and software.

- Hardware or software not available for training. - To minimize this potential risk, we have assigned the acquisition of hardware and software to a person who is a acquisitions specialist.

- Adequate consulting not available for hardware or software. - To lessen the possibility of this inadequacy, both the hardware and software will be selected from companies with a proven track record.

- Project funding withdrawn. - To help minimize this possibility, the development of this project will keep the funding organization fully informed as to the status of the project.

- Lack of support from DOE Headquarters. - To ensure support, open lines of communication will be established and maintained.

- Lack of support from other DOE field offices and contractors. - To ensure support, open lines of communication will be established and maintained. An ATMS User Group has been formed with scheduled meetings to enhance the communication.

The following riskg are less serious but could affect the orderly completion of the project:

- Hardware or software training provided too late in the project, affecting the timely completion of ATMS. - To minimize this potential 
riok, we have assessed training needs of the development staff and the user of the system. A training plan has been established to help ensure completion of training.

- ATMS Module subject Matter Experts or IRM analysta unavailable due to other commitmenta. - Every effort has been made, and will be maintained, to keep the resources which have been made available to the project to keep it on schedule. By identifying all the tasks needed to complete each module which has been identified the project and scheduling all required resources up front with management approval and aupport will help ensure the availability of resources.

- Technological difficulties (i.e., hardware or system software problems) adversely affecting development. - Again, to minimize this potential risk, we have assigned the acquisition of hardware and software to a person who is a acquigitions specialist and has had extenaive technical state-of-the-art exposure.

The last group of risks would have the least impact if they are promptly recognized and regolved.

- Task resource requirements underestimated. - The scope of the project has been defined and resources assigned. Any changes causing an shortage in resources will be handled as a change in scope, and the resource issue and schedule will be revisited.

- Failure to monitor actual versus projected resource usage and adjust accordingly. - summary reports are provided to management to monitor resource usage. A high degree of visibility with these reports will help to rectify any discrepancies.

- Software engineering problems not resolved in a timely manner. - The Technical project Manager will monitor and resolve problems to assure progress on each task.

- Major changes made to the scope of the module requirements supporting the ATMS. Major changes may include wholesale redefinition to the gcope of the project, or inclusion of major segments not defined in the module SRSE.

\subsection{MONITORING AND CONTROLLING MECHANISNS}

Monitoring and controlling the ATMS project development will be accomplished by means of a V\&V plan, peer reviews by IRM personnel the cognizant engineers and/or subject matter experts, work breakdown structure, weekly status reports, and monthly status reports. Monthly status reports will sumarize the budget status (actual versus projected), progress of each assigned task, and an overall evaluation of project development.

A work breakdown structure (WBS) (see Appendix A) is a list of proposed and anticipated tasks required to complete each major portion for each module of the ATMS development project. The WBS is an outline of each major phase into numerous tasks and sub-tasks requiring a resource. The ATMS development team, under the technical project manager's direction, will estimate the tasks 
and staff hours required for each item in the WBS. Task estimates are based on system requirements and team expertise. Regular evaluations will be made of resource usage and progress on each task.

Monitoring, managing, and staffing the project tasks will be accomplished by the technical project manager.

\subsection{STAFFINO PLAN}

The ATMS project development team will consist of the following:

- ATMS Technical Project Manager (1) - Responsible for the following: resource management, budget, schedule, and staffing related to the IRM project scope; all aspects of the ATMS design, implementation, testing, and quality; ATMS module integration; and personnel and equipment safety. Directs all ATMS staff and ensures that personnel are adequately trained to perform assigned functions; serves as the main point of contact between the IRM/ATMS project organization and all DOE personnel showing interest in the ATMS; interacts with system vendors and other interested organizations; reviews and approves all deliverables for the ATMS project; and provides the reporting interface to the IRM Department through the manager, Information scientific systems.

- ATMs Project Leads (3) - Responsible for the interfacing with the ATMS Technical Project Manager; for directing and assigning staff at their site; for the overseeing of the design, coding, documentation, configuration control, unit testing, and quality of all deliverables; workg with the user organization and ATMS Technical Project Manager to design and implement project deliverables.

- ATMS software Engineers (8) - Responsible for the design, coding, documentation, configuration control, unit testing, and quality of all deliverables; works with the user organization and ATMS project lead to design and implement project deliverables.

- ATMs support staff (6) - Responsible for the hardware and vendor provided software. This responsibility includes operating system support, database administration support and development tool support. This level of support is reguired at each developing site. These individuals will report to and interface with the ATMS project lead at their site.

- Document Production Support (1) - An individual who would represent an organizational entity responsible for technical editing, word processing, and document distribution for the ATMS; works with project team members on the production of documentation deliverables.

- Complex Wide subject Matter experts (20) - Technical support for software design and implementation. Reviews and approves documentation, attends system reviews, and serves as a resource for system design and operational requirements. 
WHC-SD-TP-SWD-002 Rev. 3

- WBC QA Engineer (1) - A WHC Quality Assurance Engineering staff member who monitors and advises IRM on various aspects of the ATMS development per the guidance in WHC-CM-4-2, Quality Assurance Nanual (WHC 1989b); inspects and approves system documentation.

- V\&V Representative (1) - An individual who would represent an organizational entity responsible for conducting V\&V activities on ATMS. NOTE: Details on the team composition and reporting methods will be found in the SWVP. 


\subsection{TECHNICAL PROCESS}

This chapter explains the methods, tools, and techniques which will be used in the development of the ATMS. It also covera the documentation of the system, configuration control of both documentation and software, acquisitions, and data management.

\subsection{METHODS, TOOLS, AND TECHNIQUES}

This section specifies the computing system, programming language(s), development methodologies, team structures, and other notations, tools, techniques, and methods to be used to specify, design, build, teat, integrate, document, deliver, modify or maintain (or both if appropriate) the ATMS deliverables. The technical standards, policies, and procedures governing development or modification (or both) of the work products and project deliverables are either included or referenced.

\subsubsection{Standards}

Applicable requirements aet forth in wHC-CM-6-1, Standard Engineering Practices (WHC 1988b), WHC-CM-3-10, Software Practices (WHC 1993a), and WHC-CM-4-2, Quality Assurance Manual, $Q R$ 19.0, "Software Quality Assurance Requirements" (WHC 1989b), will govern the plans, documents, and work activities required to produce the ATMS. Primary technical guidance and detailed document content will be in accordance with ANSI/IEEE standards.

\subsubsection{Hardware/Software}

The modules which make up the ATMS, will be developed and maintained for operational use on suNSParc Workstations ${ }^{2}$. Two such machines will be used in the development of the software. Standardized tools will be provided on these machines for the development effort.

To ensure the same look and feel across all modules within the ATMS, standard GUI interface and reporting tools will be used. Oracle Forms version 4.5 and Oracle Reports version 2.5 have been selected as the tools for this purpose. A standard set of user preferences and templates will also be provided to developing sites to aid in creating a common interface to the user.

2 sunsparc is a trademark of Sun Microsystems, Inc.

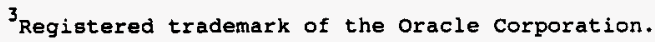

${ }^{4}$ Registered trademark of the Oracle corporation. 
When and where applicable, software used by other DOE site systems will be evaluated and adapted the ATMS. Detailed information on the ATMs software structure may be found in the ATMS software Design Description (SDD) (WHC-SD-TP-SDD-001) (WHC 1995).

User access to the computer will be through Local Area Networks (LANs), or Serial Line Interface Protocol (SLIP) servers. Computer accegs will be controlled by username/password, and access privileges to sensitive data by authorized usera will be determined and controlled by the ATMS Technical Project Manager or the ATMS Project Lead. User access tables (read, insert, update, delete) will be maintained within the applications database to control users from performing unauthorized functions, or viewing data not intended for their use. The system administration of this task will be determined on a site by site basis.

Specific requirements for data transferred from the ATMS database to other DOE Complex Databases will also be addressed in the ATMS SDD.

Applicable standards governing the transfer of data will be specified in the Design Document.

\subsubsection{Testing}

Alpha, beta, and final system acceptance tests will be conducted on the ATMS software before the system is releaged for public use at any DOE site. The ATMS Test Plan (WHC-SD-TP-TP-002) (WHC 1994) addresses all ATMS modules and integrated testing requirements. This test plan specifies the methodology to be used to ensure that a comprehensive teating sequence is performed on the system and to ensure system validation against the requirements contained in the ATMS software Requirements specification (SRS). This plan identifies the items, functions, options, and features to be tested, the testing tasks to be performed, and the required qualifications of testing personnel; describes the system acceptance criteria and includes test suspension, problem correction, and test resumption requirements.

The ATMS Test Plan has been developed in accordance with the following:

- ANSI/IEEE 1008-1987, standaro for software Unit Testing (ANSI/IEEE 1989)

- ANSI/IEEE 829-1983, Standard for Software. Test Documentation (ANSI/IEEE 1989)

- WHC-CM-6-1, Standard Engineering Practices, EP-4.2 and EP-5.8 (WHC $1988 \mathrm{~b}$ )

- WHC-CM-3-10, Software Practices, SP 3.4 and SP 10.1 (WHC 1993a)

- WHC-CM-4-2, Quality Assurance Manual, QR 19.0 (WHC 1989b). ATMS SVVP.

This plan is to be coordinated with testing activities specified in the 


\section{Q.2 DOCUNENTATION}

Documentation will be developed for the ATMS according to this project management plan and other governing documents. Section 1.4.3 lists required documentation. All custom software documentation will adhere to IEEE software engineering etandards and styles, and WHC policies and naming conventions. User documentation will be developed in accordance with ANSI/IEEE 1063-1987, Standara for Softwaro Documentation (ANSI/IEEE 1989) and will also be available in electronic format. When posgible, atandard off-the-shelf vendor documentation will be used to provide technical detail and operating instructiong for the ATMS vendor-provided hardware and software.

Technical documentation for the ATMS will be produced in a consistent and controlled manner. The documents will be produced to maximize the benefits to the project design and minimize expenditure of manpower. Before an ATMS development staff member is assigned to develop gystem documentation, the following information will be available or provided by the ATMS Technical project Manager:

- Document title and project designator

- Purpose

- Content outline

- Review and approval requirements

- Applicable interface documentation

- Applicable guidance and standards

- Task manpower and budget allocation

- Final deadine dates

- Distribution list.

Each document produced in support of the ATMS development will, as a minimum, undergo a peer, IPC, and ATMS Technical project Manager review before being submitted for approval to the ATMS Project. All significant design and test documentation serves as input to V\&V phase reviews; this requirement guarantees formal review before approval and distribution.

All documentation for ATMS has been developed according to the criteria defined by WHC-CM-6-1, Standard Engineering Practices, EP-1.7 (WHC 1988b) and WHC-CM-3-10, Software Practices (WHC 1993a). Document approval and sign-off will be by way of dated signatures (stipulated in WHC-CM-6-1) on an Engineering Data Transmittal (EDT) form (WHC form BD-7400-172-1) attached to the front of the document.

\subsection{CONFIGURATION CONTROL}

Descriptions concerning configuration control will be covered in the ATMS Configuration Management Plan (CMP), DOE/RL-93-52 (DOE-RL 1993b). 
Operational issues concerned with configuration control will be covered in the ATMS Installation Plan and the ATMS Administration and operational Guide. Where applicable, existing procedures from wHC-CM-3-10, software Practices (WHC 1993a), will be followed. The CMP addresses the following:

- Software configuration controls

- Software maintenance and application management

- Computer and data protection requirements

- computer security.

The ATMS Installation Plan will include a section that documents or references the methods to be used to maintain configuration control over ATMS equipment. Hardware configuration controls will specify the method and technology to be used to maintain a continuous record of the changes to the baseline ATMS configuration.

The ATMS CMP documents the point in the development cycle where software configuration control is to be initiated. The methods to be used for identifying software modules, controliing and implementing changes, and recording and reporting change implementation status will be stated. This section of the plan is written in accordance with WHC-CM-3-10, Software Practices (WHC 1993) and ANSI/IEEE 828-1983, standard for software Configuration Management Plans (ANSI/IEEE 1989).

Software maintenance and application planning are part of the ATMS CMP and cover the requirements for maintenance of released software for the following:

- Corrective maintenance performed specifically to overcome faults that become apparent

- Perfective maintenance performed to improve performance, maintainability, or other software attributes

- Adaptive maintenance performed to make a software product usable in a changed environment.

The ATMS CMP also provides overall direction on how to implement those activities that will support the development of a quality software product during all phases of the implementation and operations. A method must be specified which considers those actions required to guarantee that the ATMS software is traceable to the software configuration status used to produce those results. This planning guidance shall be written in accordance with WHC-CM-4-2, Section QR 19.0, Quality Assurance Manual (WHC 1989d).

A computer security plan (ATMS security Plan, DOE/RL-93-53 |DOE-RL 1993c]) has been developed according to the guidance of WHC-CM-4-7, Unclassified Computer security (WHC 1988a), for use on all ATMS computers. computer protection addresses all issues of security and physical protection (e.g., access privileges and authority) of equipment and data. 


\subsection{ACQUISITION}

The acquisition of production server hardware and all vendor software will be funded by DOE-HQ. The physical acquisition and deployment to regional sites will be handled by Richland Operations.

\subsection{DATA MANAGEMENT}

Databage structure for the ATMS will be designed and maintained in accordance with WHC-CM-2-6, Data Administration standards (WHC 1989a), and consistent with direction from RLO-ADP-1, Hanford site Date Administration Guide (DOE 1989). 


\subsection{VERIFICATION AND VAIIDATION PLANNING}

This chapter discusses planning for ATMS V\&V. Guidance to be followed, development cycle veV, and training are addressed.

\subsection{OVERVIEW}

Verification and Validation will be done by a team of people organizationally independent from development personnel. This team will write and issue the ATMS system Verification and Validation PIan (SVVP). This plan is to be developed according to WHC-CM-6-1, standard Engineering Practices, EP-4.2 (WHC 1988b), WHC-CM-3-10, Software Practices, EP-3.3 (WHC 1993), and to the standards of ANSI/IEEE 1012-1986, standard for software Verification and Validation Plans (ANSI/IEEE 1989). All VQV activities to be applied to the ATMS will be identified and stated as a requirement. The ATMS SVVP will be closely coordinated with the ATMS Test Plan. The V\&V records are quality records, and the final verification and validation review (VVR) is to serve as certification of the ATMS system.

\subsection{DEVELOPMENT CYCLE VERIFICATION AND VALIDATION}

A program of $V \& V$ will be conducted on all software used to implement the functionality of the ATMS. The V\&V program will be conducted as a parallel activity with the ATMS software development effort. The V\&V review and reports will be conducted and prepared by an individual separate from the ATMS software development team. The terminology "V\&V" can be defined as a high quality QA program for the production of software. The VQV activities, including reviews, audits, and written reports, will follow the guidance of the ATMS SVVP. An approved final ATMS VVR will serve as the system certification that ATMS is ready for operations. Validation activities associated with testing will be closely coordinated with the scope of testing specified by the ATMS Test Plan. Requirements of WHC-CM-6-1, Standard Engineering Practices (WHC 1988b), will be met.

\section{5 .3 TRATNING}

An ATMS training plan will be written by ATMS software development team and key individuals from the ATMS Userg Group. The plan will define personnel development standards required for training and system operation. The methodology for training record maintenance will be specified. Training tasks will be defined, programs developed, training conducted, and training records maintained in order to ensure that the ATMS development and maintenance staff and functional users can produce quality products and accomplish all the activities specified in this development plan. Training can be divided into the following categories.

- Software Training - Vendor training of software engineers on system operations, application programming, and system configuration will be 
required. These courses may take place at vendor facilities or on the DOE sites.

- system Administrator - Training of a system Administrator for each gerver will be required. System Administration training and support materials will be structured so that periodic repetition of the courses can be accomplished with minimum preparation and expense.

- User - Training of standard users, engineers or operations personnel will be conducted by an online training course. This training will be able to be completed at the users own speed. Completion of this training will be required prior to access to the ATMS. 


\subsection{WORK PACRAGES, SCHEDULE, AND BUDGET}

This chapter addresses the work packages, dependencies, resource requirementa, and achedule for the completion of the ATMs project.

\subsection{WORK PACKAGES}

Appendix A describes the major steps of the work breakdown structure (WBS) for the remaining tasks to be completed on this work effort for ATMS. The current tasks, hours, and schedules for WBs activities is kept up to date by the Technical Project Manager.

\subsection{DEPENDENCIES}

The major dependencies of the project are the needed hardware and personnel resources required to complete the project. These dependencies will be satisfied by providing hardware computing resources and the development staff, including ancillary support personnel required as addressed in the plan.

\subsection{RESOURCE REQUIREMENTS}

The ATMS project will require the resources identified for each delineated major tagk. A breakdown of the cost can be found in the cost Account Plan (CAP).

This plan does not include the following costs:

- DOE Staff Labor

- Subject Matter Experts Labor

- Travel Expenses for Subject Matter Experts.

\subsection{SCHEDULE}

The schedule of the uncompleted work packagea are kept by the Technical Project Manager and are updated each week. Contact the Technical project Manager for a current schedule. 
WHC-SD-TP-SWD-002 Rev. 3

\subsection{REFERENCES}

ANSI/IEEE, 1989, Software Engineering Standards, American National standards Institute and the Institute of Electrical and Electronics Engineers, New York, New York.

DoE, 1989, Hanford Site Data Administration Guide, RLO-ADP-1, U.S. Department of Energy, Washington, D.C.

DOE-RL, 1993a, Functional Requirements Document, DOE/RL-93-17, U.S. Department of Energy, Richland Field office, Richland, Washington.

DOE-RL, 1993b, ATMS Configuration Manegement Plan, DOE/RL-93-52, U.S. Department of Energy, Richland Field Office, Richland, Washington.

DOE-RL, 1993c, ATMS Security Plan, DOE/RL-93-53, U.S. Department of Energy, Richland Field office, Richland, Washington.

wHC, 1988a, Unclassified Computer security, WHC-CM-4-7, Westinghouse Hanford Company, Richland, Washington.

WHC, 1988b, Standard Engineering Practices, WHC-CM-6-1, Westinghouse Hanford Company, Richland, Washington.

WHC, 1989a, Data Administration Standards, WHC-CM-2-6, Westinghouse Hanford Company, Richland, Washington.

WHC, 1989b, Quality Assurance, WHC-CM-4-2, Westinghouse Hanford Company, Richland, washington.

WHC, 1993a, Software Practices, WHC-CM-3-10, Westinghouse Hanford Company, Richland, Washington.

WHC, 1993b, ATMS Software Documentation Plan, WHC-SD-TP-PLN-007, Rev. 0 , Westinghouse Hanford Company, Richland, Washington.

WHC, 1994b, ATMS Test Plan, WHC-SD-TP-TP-002, Westinghouse Hanford Company, Richland, washington.

WHC, 1995a, ATMS Software Design Description, WHC-SD-TP-SDD-001, Rev, 1, Westinghouse Hanford Company, Richland, Washington.

WHC, 1995b, ATMS Software Project Management Plan, WHC-SD-TP-SWD-002, Rev. 2, Westinghouse Hanford Company, Richland, Washington. 
WHC-SD-TP-SWD-002 Rev. 3

APPENDIX A

ATMS WORK BREARDOWN STRUCTURE

A- 1 
WHC-SD-TP-SWD-002 Rev. 3

This page intentionally left blank.

$A-2$ 


\section{DESTGN PHASE}

1.0 ACOUISITIONS PLANNING

1. 1 ACQUIRE REMAINING FOUR PRODUCTION SERVERS

2.0 COMPIETE SOFTWARE DESIGN DESCRIPTION (SDD)

2.1 PREPARE FINAL SOFTWARE DESIGN DOCUMENT

2.2 SDD REVIEW FOR APPROVAL

2.3 VEV DESIGN REPORT

2.4 SDD COMPLETE (REV O)

3.0 CONSTRUCTION

3.1 CODE INTERFACES SMAC AND GSA

3.2 CODE 2 SYSTEM ADMINISTRATION SCREENS

3.3 CODE JOURNALING AUDIT PROCESSES

3.7 CODE REMAINING VERIFICATION EDITS FOR EDI

\subsection{DATA LOADING PLAN}

4.1 FINALIZE THE CONVERSION PLAN

4.2 CONVERSION PLAN REVIEW AND ACCEPTANCE

4.3 CONVERSION PLAN COMPLETE (REV O)

\subsection{CONVERSION CONSTRUCTION AND CERTIFICATION}

5.1 DATA IOAD CONSTRUCTION

5.2 DATA LOAD PROGRAM CERTIFICATION

5.3 DATA CERTIFICATION 
WHC-SD-TP-SWD-002 Rev. 3

\subsection{ATUS STAGING AND IMPLENENTATION}

6. 1 FINALIZE DATABASE AND FILE STRUCTURE ON THE PRODUCTION STAGING MACHINE

6.2 UPDATE IMPLEMENTATION PLAN, REVIEW AND ACCEPTANCE

6.3 IMPLEMENTATION PLAN (REV 3) AND STAGING COMPLETE

\subsection{ATKS TEST PLAN UPDATE}

7.1 PREPARE ATMS TEST PLAN

7.2 TEST PLAN REVIEW AND ACCEPTANCE

| 7.3 TEST PLAN COMPLETE (REV 2)

\subsection{USER MANUAL}

8.1 PREPARE USER MANUAL

8.2 USER MANUAL REVIEW AND ACCEPTANCE

8.3 USER MANUAL COMPLETE (REV 2)

\subsection{AMYS TRAINING PIAN UPDATE}

9.1 PREPARE ATMS TRAINING CODE

9.2 ASSIST IN THE DEVELOPMENT OF THE ATMS TRAINING COURSE

9.2 AUTOMATED TRAINING REVIEW AND ACCEPTANCE

\section{IMPLEMENTATION PHASE}

\subsection{PREPARE IMPLEMENTATION SITES}

10.1 CONFIGURE PRODUCTION SERVERS

10.2 SHIP SERVERS TO PRODUCTION SITES

10.3 AID IN THE SITE INSTALLATIONS ON NETWORKS

\section{TEST PHASE}

\subsection{READINESS TO TEST}

11.1 VEV REVIEW REPORT

Each program or processing entity is described in detail and within context to the application to the entire developer team and checked for A-4 
technical correctness. The source code is traced to corresponding SDD design entity and desk checked for correctness, consistency, completeness, accuracy and testability. A VVR is issued describing this work effort.

\subsection{QA CHECKPOINT REVIEW}

QA reviews the results of the VQV process used during prior phases in readiness to certify the eystem.

\subsection{TEST READINESS REVIEW}

A formal review of the software is conducted to ensure completion of software construction, user documentation, and test procedure specification, and to verify the software is ready to be formally tested against initial software requirements.

\subsection{CERTIFICATION}

12.1 CONDUCT UNIT TESTING

Each constructed program is tested by its author for accuracy to the approved design then tested by the developers as a component of the system. Unit testing should be performed in such detail that the system could actually be implemented upon successful completion of this task.

12.2 CONDUCT SYSTEM (INTEGRATION) TESTING

The system is tested and certified according to approved test procedures. The types of testing done in this activity include component testing, system testing and acceptance testing.

\subsection{PREPARE TEST REPORT}

A Test Report is issued detailing the results of the certification work effort.

\section{INSTALLATION PHASE}

\subsection{INSTALLATION, ACCEPTANCE AND TRAINING}

\subsection{OPERATING PROCEDURES}

Complete all operating procedures and update the User Manual, if needed.

\subsection{UPDATE CONFIGURATION MANAGEMENT PLAN}

The Configuration Management Plan will need to be updated with any changes required to support the maintenance of the system. This will provide developers with a consistent method which will meet the ever changing needs of the users. This plan will include coding standards, release procedures, backup and agreed levels of support matrix. 
13.3 CMP REVIEW AND ACCEPTANCE

The IPC, IRM engineers and operations, $Q A$, and V\&V meet to review and accept the changes to the CMP.

13.4 CMP COMPLETE (REV 2)

13.5 OPERATIONS (MO) REVIEW

Conduct IRM management orientation (MO) to the system at each site. The management orientation should include installation, communication procedures, and answer all management questions concerning operation and maintenance of the system.

13.6 PRODUCTION INSTALLATION

Install all software and verify operating system and RDBMS installation on the customer' $g$ hardware for final turnover to the customer. Ensure version controls are in place.

13.7 PRODUCTION ACCEPTANCE

Ensure all software is working and installation tasks are complete according to the Implementation Plan.

13.8 USER TRAINING

Conduct training with system Adminiatratore according to the approved Training plan. This training will be made available to give very specific training to system Administrator for each site. This will include training on the on-line training system which is available to all users.

\subsection{CUSTOMER ACCEPTANCE}

Cugtomer has final approval of the system after test results have satisfactorily accomplished documented acceptance criteria.

13.10 VVR (FINAL)

Prepare the Final VaV Report.

ONGOING ADMINISTRATIVE PROCEDURES

\subsection{VEV REVIEW/TRAINING}

\subsection{DELIVERABLE REVIEWS}

Each developer is responsible for reviewing and commenting each project deliverable. 


\subsection{WALKTHROUGH PARTICIPATION}

Each developer and subject matter experts from other sites are to attend and participate in formal technical reviews for the modules for which they are involved.

\subsection{PROJECT MANAGEMENT}

\subsection{STATUS REPORTING}

A written status report will be submitted weekly by the ATMS Technical Project Manager to the IPC, ATMS developers, and cognizant management. A monthly profect status and resource consumption report will be submitted to the IPC and cognizant management by the $a i x t h$ of each month. Monthly functional review of ATMS progress will be conducted.

15.2 PROJECT REVIEWS

Attending any reviews which are required for review of the project.

15.3 ANALYZE RESOURCE CONSUMPTION

The ATMS Technical Project Manager will monitor and control resource allocation and resource usage against forecasta.

\subsection{MAINTAIN PROJECT NOTEBOOK}

A Project Notebook will be maintained.

\subsection{NEXT YEAR PLANNING}

Budget forecasts and activity recommendations will be made for the next year.

15.6 CHANGE REQUEST PROCESSING

The ATMS Technical Project Manager will administer and coordinate approved change requests. 
WHC-SD-TP-SWD-002 Rev. 3

This page intentionally left blank.

A-8 


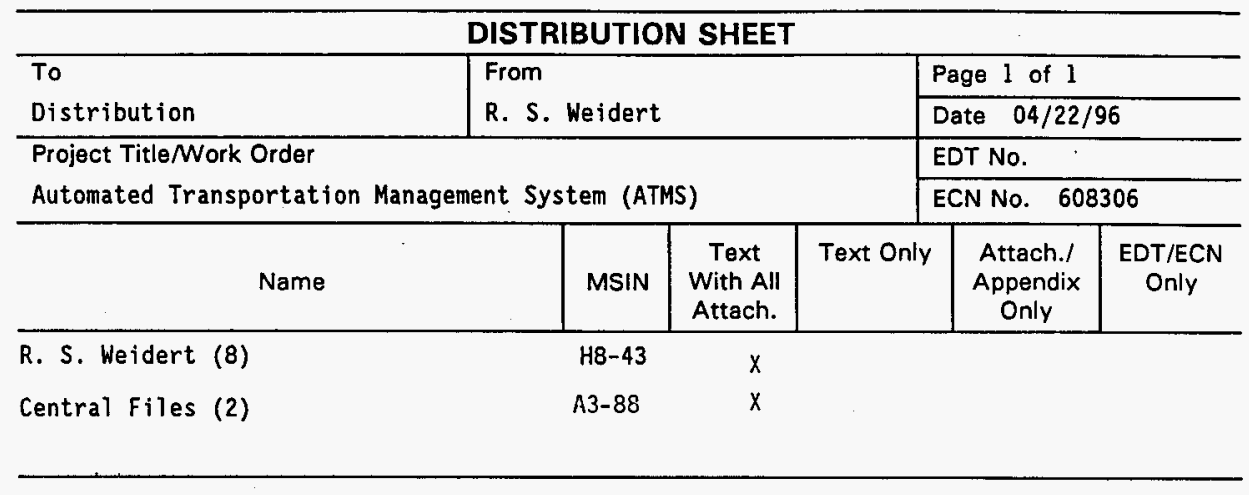

